Article

\title{
Effect of Stannic Species Modification on the Acidity of Silicalite-1 and Its Enhancement in Transforming Ethylenediamine to Heterocyclic Amines
}

\author{
Yongxin Zhang, Long Lin, Xiaoming Zheng, Chunyan Liu, Quanren Zhu and Hongchen Guo * \\ Department of Catalytical Chemistry and Engineering, State Key Laboratory of Fine Chemicals, \\ Dalian University of Technology, Dalian 116024, China; gychzyx@mail.dlut.edu.cn (Y.Z.); \\ linlong@mail.dlut.edu.cn (L.L.); 1809584156@mail.dlut.edu.cn (X.Z.); chunyanliuzh@163.com (C.L.); \\ zhuquanren19871116@126.com (Q.Z.) \\ * Correspondence: hongchenguo@dlut.edu.cn
}

Received: 17 January 2020; Accepted: 7 February 2020; Published: 10 February 2020

\begin{abstract}
In this study, a series of $\mathrm{SnO}_{2}$ modified zeolite catalysts (Snx-S-1; $\mathrm{x}$ is the weight percentage of $\mathrm{Sn}$ ) were prepared with $\mathrm{SnCl}_{2}$ and a defective Silicalite-1 (S-1) zeolite via facile deposition-precipitation method. It was found that the stannic species modified all-silica zeolite catalysts were active for the intermolecular condensation of ethylenediamine (EDA) to 1, 2-Diazabicyclo [2, 2, 2] octane (TEDA) and piperazine (PIP). The best catalyst Sn6-S-1 (6 wt.\% Sn loading) showed 86\% EDA conversion and $93 \%$ total selectivity to TEDA and PIP. By contrast, the defective S-1 zeolite parent showed only approximately 9\% EDA conversion under the same conditions. With the help of catalyst characterization techniques including hydroxyl vibration and pyridine adsorption FT-IR spectroscopy (transmission mode), the enhancement of the catalytic activity of the $\mathrm{SnO}_{2}$ modified zeolite catalysts (Snx-S-1) was mainly attributed to the formation of mild Lewis acid sites in the siliceous zeolite. Both the hydroxyl nests of the defective S- 1 zeolite and the dispersed $\mathrm{SnO}_{2}$ clusters should be the important factors for the formation of mild Lewis acid sites on the modified zeolite. Based on the catalytic performance of the modified zeolite in the conversion of EDA to PIP and TEDA, it is inferred that the mildly acidified defective S-1 zeolite by the $\mathrm{SnO}_{2}$ deposition modification might become a very active and durable catalyst for reactions involving strongly alkaline reactants and products.
\end{abstract}

Keywords: defective Silicalite-1; $\mathrm{SnO}_{2}$ modification; acidity; condensation of ethylenediamine

\section{Introduction}

Zeolitic solid acids with strong acidic sites have attracted attention in the past because they are good catalysts for a long list of hydrocarbon transformation reactions in both oil refining and petrochemical industries [1]. Aluminosilicate zeolites are generally strongly acidized, and they belong to a big family that has already more than 200 different topologic structures so far [2]. However, the conversions of reactants with strong basicity such as nitrogen-containing compounds [3], which are useful reactions for the synthesis of functional organic molecules, often need zeolitic solid acids with mild acidity. One important example of this kind of reaction is the conversion of ethylenediamine (EDA) to heterocyclic amines like 1, 2-Diazabicyclo [2, 2, 2] octane (TEDA) and piperazine (PIP). TEDA is an excellent catalyst for producing polyurethane foams [4], while PIP has found a lot of applications in medical and industrial fields [5]. PIP can also be used as an antioxidant to scavenge free radicals and as a promoter for the removal and recovery of $\mathrm{CO}_{2}[6]$.

In the 1990s, H-ZSM-5 zeolite had been used as catalyst for the conversion of EDA to TEDA and PIP $[7,8]$. Generally, H-ZSM-5 zeolite has high initial EDA conversion, but it deactivates fast due to the strong adsorption of highly alkaline EDA, TEDA, and PIP on the strong acid sites (bridging 
hydroxyl groups) of H-ZSM-5 zeolite. For this reason, some modification methods such as alkali metal ion modification [7] and dealumination [9], etc. have been proposed to weaken the strength of acidic sites in H-ZSM-5. However, such efforts often cause negative effects such as worse diffusivity due to pore channel blocking. In 2003, titanium silicalite-1 (TS-1) was patented for the reaction of EDA to TEDA and PIP [10]. Later, people conducted a detailed study on the intermolecular condensation of EDA to make PIP and TEDA over TS-1 zeolite [11]. Silicalite-1 (S-1) zeolite is an aluminum-free crystalline silicate with the same MFI topological framework as the Al-containing ZSM-5 zeolite and Ti-containing silicate zeolite (TS-1). It is well known that the presence of defective sites in S-1 lattice can form mild acidity (silanol nests). The defective S-1 zeolite has been reported as an active Beckmann rearrangement catalyst [12-15]. However, previous study indicated that the defective S-1 zeolite itself was not very active and selective for the reaction of EDA to TEDA and PIP, giving only 19.5\% EDA conversion and $7.5 \%$ TEDA selectivity [11]. This implies that the acidity of defective S- 1 is too weak to be an efficient catalyst for the conversion of EDA.

In recent years, $S n-\beta$ zeolite has attracted increasing attention because its isolated framework $\mathrm{Sn}$ is an active Lewis acid site for many reactions, including Baeyer-Villiger oxidation, sugar isomerization, and Meerwein-Ponndorf-Verley reaction [16,17]. Sn-MFI zeolite was also found active for the hydroxylation of phenol [18] and the synthesis of N-methylaniline by aniline alkylation with methanol [19], etc. Sn-containing zeolites can be obtained by direct hydrothermal synthesis. However, the direct hydrothermal synthesis is a time-consuming, corrosive, and noxious route due to the use of a large amount of HF. Recently, Dapsens et al. [20-22] developed an alkaline-assisted metalation method to prepare Sn-MFI zeolite by simply contacting a commercial S-1 zeolite with a Sn-containing alkaline solution. It seems that the alkaline-assisted metalation strategy is environmentally benign and relatively easy to scale up.

In this study, inspired by the Lewis acidity of Sn- $\beta$ zeolite and the facile alkaline-assisted metalation strategy in making Sn-containing zeolite, we attempted to enhance the acidity of a defective S-1 zeolite by introducing different amounts of Sn into the defective S-1 zeolite with deposition-precipitation (DP) method. In this way, a series of Sn-containing S-1 zeolites with different Sn loadings were obtained and characterized by different techniques. The intermolecular condensation of EDA to TEDA and PIP was also employed as a probe reaction to characterize the catalytic performance of the acidity of the Sn-containing S-1 zeolites. Results indicate that the introduction of Sn species into the defective S- 1 is a good way to activate the originally less active material, which showed remarkably enhanced catalytic activity and selectivity in the conversion of EDA compared with the defective S- 1 zeolite parent. To the best of our knowledge, such work has not been reported so far. We think that the Sn-containing S-1 zeolite, as a kind of mild solid acid catalyst, might find many applications in the future, especially in the area of transforming strongly alkaline $\mathrm{N}$-containing organic molecules.

\section{Results and Discussion}

\subsection{Sn Species and their Locations in the Modified Defective S-1 Zeolite}

First of all, we would like to note that when the defective S-1 zeolite was used as parent for the DP modification (see experimental section for detail), the resulted catalysts were coded as Snx-S-1, where $x$ denoted the weight percentage of $S n$ in the catalyst. For the purpose of comparison, a "perfect" S-1 zeolite (coded as Si-S-1) with low density of hydroxyl nests was prepared by treating the defective S-1 zeolite parent with $\left(\mathrm{NH}_{4}\right)_{2} \mathrm{SiF}_{6}$ aqueous solution. The Si-S-1 zeolite together with a fume $\mathrm{SiO}_{2}$ matrix were also subjected to the DP modification, and the resulting catalysts were named Sn3-Si-S-1 and $\mathrm{Sn} 3$-fume $\mathrm{SiO}_{2}$, respectively. Here, the $\mathrm{Sn}$ loading was fixed at $3 \mathrm{wt} . \%$.

The scanning electron microscope (SEM) characterization revealed that the defective S-1 zeolite parent was composed of 400-500 nm clean plate crystals. However, the surface of Sn-containing samples (Snx-S-1, $x=1,3,6,8)$ was attached by a lot of small aggregates, as shown by Figure 1 . As the number of the aggregates in the samples increased with $\operatorname{Sn}$ loading $(\operatorname{Snx}, x=1,3,6,8(w t . \%))$, it is 
reasonable to assign them to Sn species. Table 1 indicates that treating the defective S- 1 zeolite parent by the DP method only caused a marginal decrease of the zeolitic specific surface area and that the decrease was mainly due to the decline of external surface area. In view of the fact that the external surface of the Sn-containing zeolitic samples (Snx-S-1) was attached by many small aggregates of Sn species, the decline of their external surface area is reasonable.

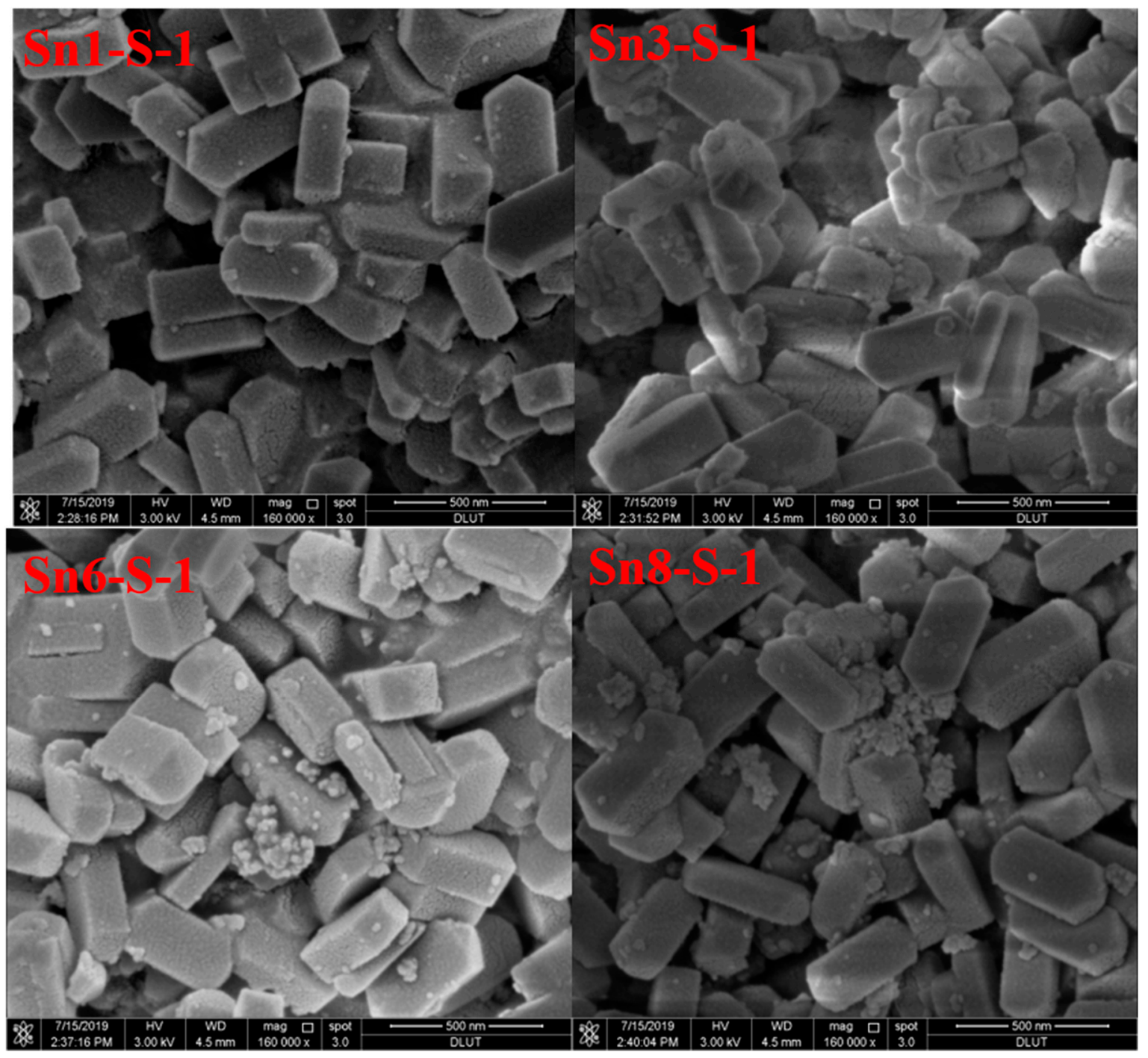

Figure 1. SEM images of Sn-containing defective S-1 (Snx-S-1) zeolite samples.

Table 1. Textural properties of defective S-1 zeolite and its Sn-containing counterparts (Snx-S-1).

\begin{tabular}{|c|c|c|c|c|c|c|}
\hline Sample & $\begin{array}{l}\text { Sn content } \\
\text { (wt. } \%)\end{array}$ & $\begin{array}{c}S_{\mathrm{BET}} \\
\left(\mathrm{m}^{2} \mathrm{~g}^{-1}\right)\end{array}$ & $\begin{array}{c}S_{\text {micro }} \\
\left(\mathrm{m}^{2} \mathrm{~g}^{-1}\right)\end{array}$ & $\begin{array}{c}S_{\text {extra }} \\
\left(\mathrm{m}^{2} \mathrm{~g}^{-1}\right)\end{array}$ & $\begin{array}{c}V_{\text {tol }} \\
\left(\mathrm{cm}^{3} \mathrm{~g}^{-1}\right)\end{array}$ & $\begin{array}{c}V_{\text {micro }} \\
\left(\mathrm{cm}^{3} \mathrm{~g}^{-1}\right)\end{array}$ \\
\hline S-1 & 0 & 379 & 288 & 91 & 0.23 & 0.14 \\
\hline Sn1-S-1 & 1 & 371 & 279 & 92 & 0.23 & 0.13 \\
\hline Sn3-S-1 & 3 & 361 & 298 & 63 & 0.23 & 0.15 \\
\hline Sn6-S-1 & 6 & 366 & 300 & 66 & 0.23 & 0.14 \\
\hline Sn8-S-1 & 8 & 364 & 289 & 76 & 0.22 & 0.13 \\
\hline
\end{tabular}

Figure 2 shows the UV-VIS spectra of Sn-containing catalysts with different matrixes (A) and the Sn-containing defective S-1 zeolite catalysts with different Sn loadings (B). So far, the UV-VIS spectroscopic technique has been widely used as an informative characterization method for Sn species 
in Sn-containing zeolites and molecular sieves [16]. Generally, from UV-VIS spectra, three kinds of Sn species have been identified in these Sn-containing materials. They are isolated tetracoordinated framework $\mathrm{Sn}$ species, nano-sized $\mathrm{SnO}_{2}$ clusters, and bulky $\mathrm{SnO}_{2}$ particles, corresponding to UV absorption at about 200-220 nm, 230-255 nm, and 280-290 nm, respectively [20,23-26]. In the present work, the absence of 200-220 nm absorption band for the Sn-containing samples with different matrixes (Figure 2A) and the Sn-containing defective S-1 zeolite samples with different Sn loadings (Figure 2B) indicates that there is substantially no isolated tetrahedral Sn species in these Sn-containing materials. That is, the DP process used in this study did not introduce Sn atoms into the zeolitic framework of S-1. However, all the samples had absorption bands at around $230 \mathrm{~nm}$ and $270 \mathrm{~nm}$ instead, and their intensities gained with the increase of $\mathrm{Sn}$ loading. Thus, from the absorption bands at around $230 \mathrm{~nm}$ and $270 \mathrm{~nm}$, it is concluded that the Sn species in the catalysts of this study should mainly exist in the forms of hexa-coordinated nano-sized $\mathrm{SnO}_{2}$ clusters and bulky $\mathrm{SnO}_{2}$ species.
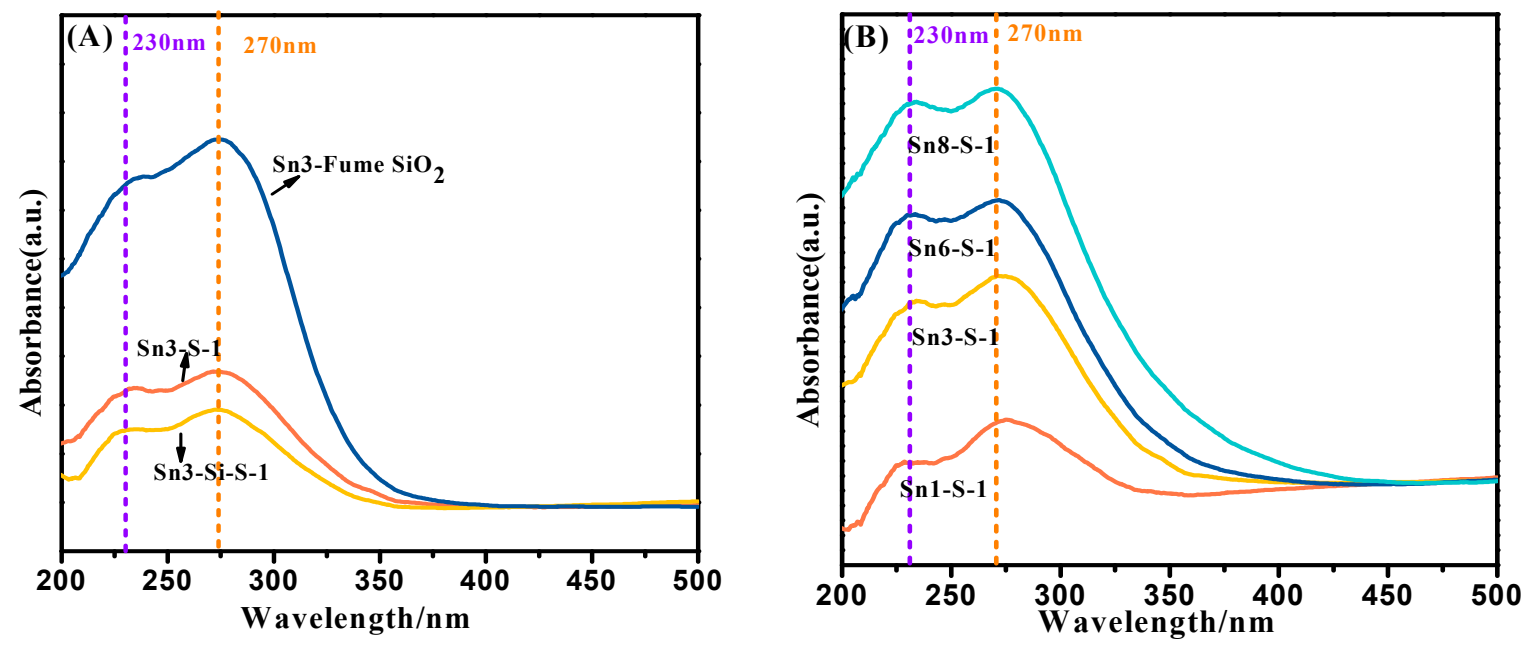

Figure 2. UV-VIS spectra of Sn-containing catalysts with different matrixes (A) and the Sn-containing defective S-1 zeolite catalysts with different Sn loadings (B).

The $\mathrm{H}_{2}$-TPR profiles in Figure 3 show that, roughly speaking, there are two kinds of hydrogen-consuming peaks in the Sn-containing catalysts. The peak centered at around $500{ }^{\circ} \mathrm{C}$ could be assigned to nano-sized $\mathrm{SnO}_{2}$ clusters, while the other peak centered around $600{ }^{\circ} \mathrm{C}$ could be assigned to the bulk $\mathrm{SnO}_{2}$ species [27]. The profiles of $\mathrm{H}_{2}$-TPR suggested that the defective S-1 zeolite matrix facilitated the formation of nano-sized $\mathrm{SnO}_{2}$ clusters in the catalyst (Sn3-S-1), while the "perfect" S-1 zeolite matrix that had low density of hydroxyl nests led to the formation of more bulky $\mathrm{SnO}_{2}$ particles and fewer $\mathrm{SnO}_{2}$ clusters in the catalyst (Sn3-Si-S-1). In addition, for the defective S-1 zeolite matrix, the increase of the $\mathrm{Sn}$ loading resulted in the increase of the content of bulky $\mathrm{SnO}_{2}$ particles. This is easy to understand. Nevertheless, it is interesting to note that the deposition of $\mathrm{SnO}_{2}$ onto the amorphous fume $\mathrm{SiO}_{2}$ matrix also formed a large number of nano-sized $\mathrm{SnO}_{2}$ clusters. To this, we speculate that the abundant surface silanols of fume $\mathrm{SiO}_{2}$ should be attributed. 

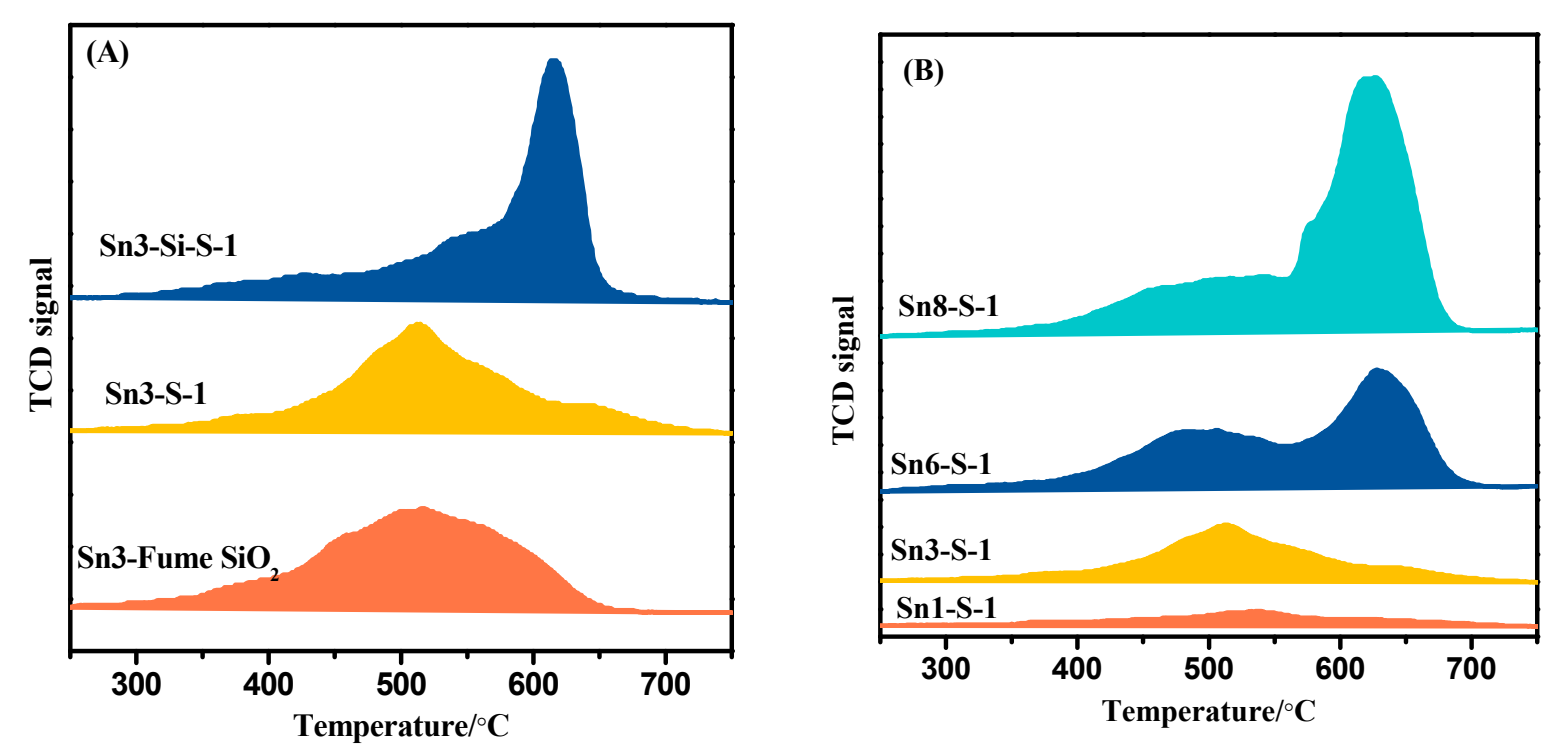

Figure 3. $\mathrm{H}_{2}$-TPR profiles of Sn-containing catalysts with different matrixes (A) and the Sn-containing defective S-1 zeolite catalysts with different Sn loadings (B).

As shown in Figure 4, in agreement with the previous study [28], the hydroxyl stretching FT-IR spectra of the fume $\mathrm{SiO}_{2}$ matrix had a very intensive and sharp band at $3745 \mathrm{~cm}^{-1}$ in its IR spectrum. This band can be assigned to the stretching mode of surface isolated silanols. The tail at the low-frequency side of the main band was a complex, which is supposed to relate to the stretching mode of geminal silanols and weakly perturbed vicinal silanols [28]. In short, the surface of the amorphous fume $\mathrm{SiO}_{2}$ matrix was rich in hydroxyls, and at least part of them were relatively active (for example, the weakly perturbed vicinal silanols). Different from the fume $\mathrm{SiO}_{2}$, the hydroxyl IR spectrum of the defective S-1 zeolite featured three weak bands at $3740 \mathrm{~cm}^{-1}, 3725 \mathrm{~cm}^{-1}$, and $3680 \mathrm{~cm}^{-1}$, and one large and broad band centered at around $3450 \mathrm{~cm}^{-1}$. These bands could be assigned to external surface isolated silanols, internal surface isolated silanols, weakly hydrogen-bonded vicinal silanols, and medium-strength hydrogen-bonded silanol nests, respectively [29]. Except for the external surface isolated silanols, the other internal surface hydroxyls were expected to be located in the hydroxyl nests of the defective S-1 zeolite. Compared with the defective S-1 zeolite, a big difference of the "perfect" S-1 zeolite, Si-S-1, obtained with $\left(\mathrm{NH}_{4}\right)_{2} \mathrm{SiF}_{6}$ aqueous solution treatment was the lack of both $3680 \mathrm{~cm}^{-1}$ and $3450 \mathrm{~cm}^{-1}$ bands. This means that the treatment of the defective S-1 zeolite with $\left(\mathrm{NH}_{4}\right)_{2} \mathrm{SiF}_{6}$ had effectively repaired most of the defects of the original zeolite parent. When $3 \mathrm{wt}$.\% Sn was deposited into these matrixes by DP method, it was easy to find that the absorptions of all the silanol groups on the different matrixes became weakened to certain degrees (Figure 4B-D). This phenomenon indicates that $\mathrm{SnO}_{2}$ was deposited on both external and internal surfaces of the S-1 zeolites. From Figure 5 it can be seen that when Sn loading was small (e.g., Sn loading $3.0 \mathrm{wt} . \%$ ), the deposit of the $\mathrm{Sn}$ resulted in relatively more considerable attenuation of $3450 \mathrm{~cm}^{-1}, 3680 \mathrm{~cm}^{-1}$, and $3725 \mathrm{~cm}^{-1}$ bands, if the intensity of the $3740 \mathrm{~cm}^{-1}$ band is used as a reference. This means that at low-level $\mathrm{Sn}$ loading, the $\mathrm{SnO}_{2}$ species were mainly deposited into the internal hydroxyl nests of the defective S-1 zeolite. As was mentioned above in the $\mathrm{H}_{2}$-TPR characterization, at such a low $\mathrm{Sn}$ loading level the $\mathrm{SnO}_{2}$ species mainly existed as nano-sized $\mathrm{SnO}_{2}$ clusters. When Sn loading was big enough (8.0 wt.\%, for example), on the other hand, the deposit of $\mathrm{SnO}_{2}$ on the defective S-1 zeolite also resulted in the obvious attenuation of the $3740 \mathrm{~cm}^{-1}$ band as well. This indicates that the excess $\mathrm{SnO}_{2}$ species were deposited on the external surface of the defective S-1 zeolite if Sn loading was high. Therefore, the results of hydroxyl stretching FT-IR spectroscopy agreed well with those of $\mathrm{H}_{2}$-TPR characterization. 

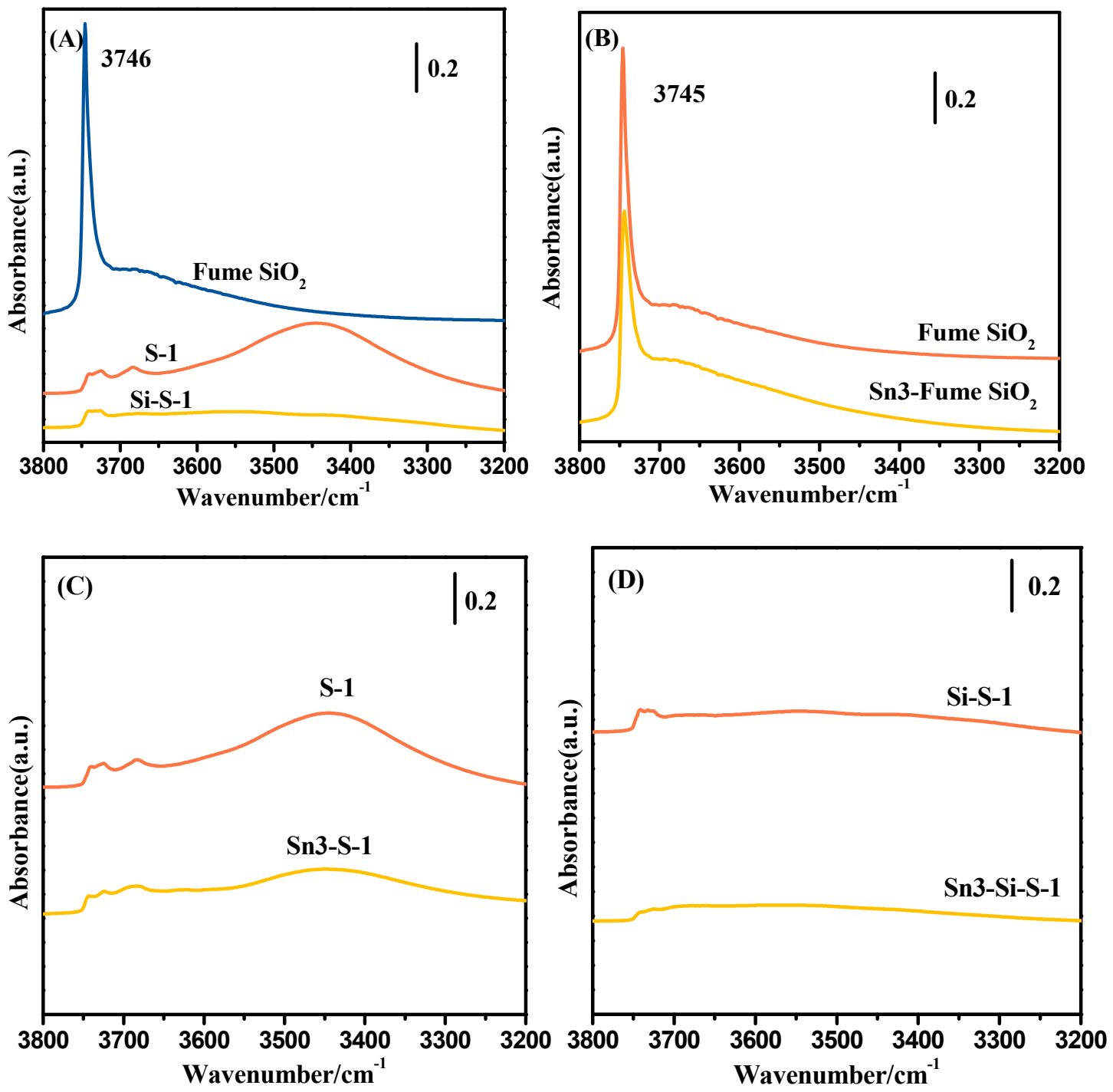

Figure 4. Hydroxyl stretching FT-IR spectra of different samples: S-1, Si-S-1, and fume $\mathrm{SiO}_{2}$ matrixes (A); fume $\mathrm{SiO}_{2}$ and Sn3-fume $\mathrm{SiO}_{2}$ (B); S-1 and Sn3-S-1 (C), Si-S-1 and Sn3-Si-S-1 (D).

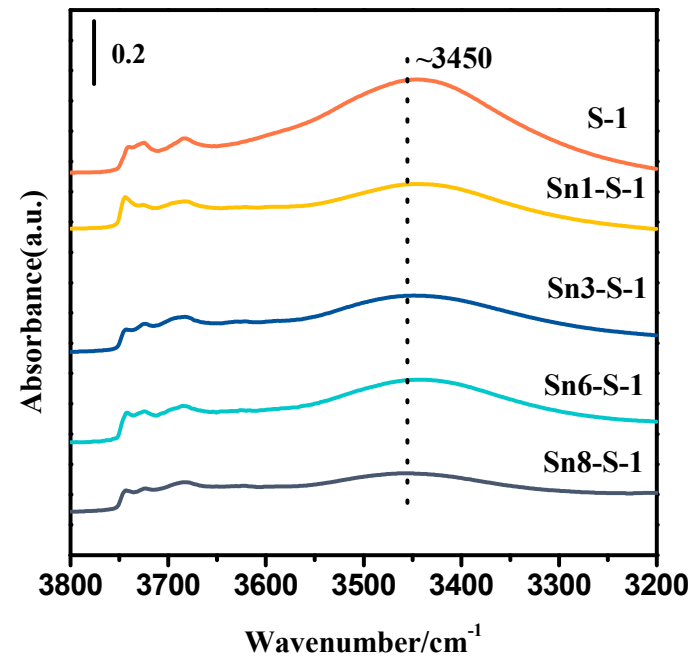

Figure 5. Hydroxyl stretching FI-IR spectra of defective S-1 and the Sn-containing defective S-1 zeolite catalysts with different Sn loadings. 


\subsection{Acidity of the Sn-Containing Defective S-1 Zeolite}

Pyridine adsorption FT-IR spectroscopy is currently a commonly adopted method for determining the type and number of acid sites of Sn-containing zeolites and molecular sieves. According to the literature reports [30-37], the Sn-containing zeolites and molecular sieves mainly have Lewis acid sites, and they usually give pyridine absorption bands in the range of 1450 to $1455 \mathrm{~cm}^{-1}$ and 1610 to 1615 $\mathrm{cm}^{-1}$. These bands are often accompanied by another important band at $1490 \mathrm{~cm}^{-1}$, which is generally considered as the contribution of pyridine adsorbed on both Brønsted acid sites and Lewis acid sites. However, in the Sn-containing zeolites and molecular sieves, Brønsted acid sites (1540-1545 $\left.\mathrm{cm}^{-1}\right)$ are seldom detectable unless a small number of trivalent metal ions such as $\mathrm{Al}^{3+}$ ions appear in the zeolitic framework as a result of impurity or survival $[25,34]$. Therefore, in the cases of Brønsted acid sites being undetectable, the band at around $1490 \mathrm{~cm}^{-1}$ was directly assigned to Lewis acid sites by some researchers [31,33]. In addition to the abovementioned features, the bands related to hydrogen-bonded pyridine (at ca. 1445, 1485, and $1596 \mathrm{~cm}^{-1}$ ) [37] and the bands belonging to physically adsorbed pyridines (at ca. 1438 and $1589 \mathrm{~cm}^{-1}$ ) [11] may also be observed. In some studies, there are bands in between 1575 and $1581 \mathrm{~cm}^{-1}$, though their assignments are still disputed [11,35].

The pyridine adsorption FT-IR spectra of Sn-containing catalysts with different matrixes and Sn-containing defective S-1 zeolite catalysts with different Sn loadings are shown by Figures 6 and 7 . The dependences of the number of Lewis acid sites of the catalysts on matrix and Sn loading are illustrated by Figure 8, where the number of Lewis acid sites of the catalysts was determined with the $1455 \mathrm{~cm}^{-1}$ band on the their pyridine adsorption FT-IR spectra evacuated at $350{ }^{\circ} \mathrm{C}$, following the reported procedures $[38,39]$. From Figure $6 \mathrm{~A}$ it can be seen that, after being evacuated at $200^{\circ} \mathrm{C}$, all the Sn-containing samples except the one obtained with fume $\mathrm{SiO}_{2}$ matrix exhibited very similar absorption bands, corresponding to physically adsorbed pyridines $\left(1438 \mathrm{~cm}^{-1}\right.$ and $\left.1589 \mathrm{~cm}^{-1}\right)$, hydrogen-bonded pyridines $\left(1446 \mathrm{~cm}^{-1}, 1485 \mathrm{~cm}^{-1}\right.$, and $\left.1598 \mathrm{~cm}^{-1}\right)$, and the Lewis sites bonded pyridines $\left(1455 \mathrm{~cm}^{-1}\right.$ and $1614 \mathrm{~cm}^{-1}$, both were shoulder peaks), respectively. The typical feature of Brønsted acid sites in the range of 1540 to $1545 \mathrm{~cm}^{-1}$ was not detectable for all Sn-containing samples of this study. However, from the complex in the region of 1450 to $1500 \mathrm{~cm}^{-1}$, the $1490 \mathrm{~cm}^{-1}$ band can be found. Therefore, by referring to what has been done in the literature [31,33], here we simply assign the $1490 \mathrm{~cm}^{-1}$ band to the pyridines adsorbed on Lewis sites. Different from the Sn-containing zeolitic samples, which had a very intensive absorption band at around $1580 \mathrm{~cm}^{-1}$ and an intensive band complex in the area of 1450 to $1500 \mathrm{~cm}^{-1}$, Sn-containing fume $\mathrm{SiO}_{2}$ catalyst had a weak band at $1580 \mathrm{~cm}^{-1}$ and a very weak band in the area of 1450 to $1500 \mathrm{~cm}^{-1}$. In addition, the $\mathrm{Sn}$-containing fume $\mathrm{SiO}_{2}$ catalyst also lacked the bands at $1438 \mathrm{~cm}^{-1}$ and $1614 \mathrm{~cm}^{-1}$. After degassing at $350^{\circ} \mathrm{C}$, the bands related to physically adsorbed pyridines $\left(1438 \mathrm{~cm}^{-1}\right.$ and $\left.1589 \mathrm{~cm}^{-1}\right)$ basically disappeared. Meanwhile, the hydrogen-bonded pyridines related band at $1485 \mathrm{~cm}^{-1}$, which was a component of the band complex in the area of 1450 to $1500 \mathrm{~cm}^{-1}$, also disappeared due to the high-temperature treatment.

Figure 7 clearly shows that the defective S- 1 zeolite only showed a small number of Lewis acid sites as indicated by the weak bands of pyridine adsorption (degassed at $350{ }^{\circ} \mathrm{C}$ ) at $1455 \mathrm{~cm}^{-1}, 1614 \mathrm{~cm}^{-1}$, and $1490 \mathrm{~cm}^{-1}$ as well. Although the abundant existence of hydroxyl nests in the defective S-1 zeolite forecasted the possession of Brønsted acidity, the typical feature of Brønsted acid sites in the range of 1540 to $1545 \mathrm{~cm}^{-1}$ did not appear in the spectrum. This means that the Brønsted acidity of the intrinsic defective zeolite was too weak to be detectable by pyridine adsorption. As to the origin of the Lewis acidity in the defective S-1 zeolite, there is no explicit statement in the literature so far. The dehydroxylation of the hydroxyl nests of the defective S- 1 zeolite at elevated temperature could be the main cause [40].

After being treated by the DP method, $\mathrm{SnO}_{2}$ species were deposited to the defective $\mathrm{S}-1$ zeolite, which resulted in the pronounced increase of the intensities of the Lewis acid sites related absorption bands at $1455 \mathrm{~cm}^{-1}, 1614 \mathrm{~cm}^{-1}$ and $1490 \mathrm{~cm}^{-1}$. Furthermore, it seems that the increase of the Sn loading ( when the Sn loading was less than $6 \mathrm{wt} . \%$ ) was accompanied by the increase of the intensities of the Lewis acid related absorption bands at $1455 \mathrm{~cm}^{-1}, 1614 \mathrm{~cm}^{-1}$, and $1490 \mathrm{~cm}^{-1}$. These phenomena 
clearly indicate that the stannic species modification via the DP process can notably enhance the Lewis acid amount and acid strength of the defective S-1 zeolite. However, just as is indicated by Figure 7A, the same stannic species modification method does not give so many Lewis acid sites on the matrixes of amorphous fume $\mathrm{SiO}_{2}$ and the "perfect" S-1 zeolite with low density of hydroxyl nests obtained with $\left(\mathrm{NH}_{4}\right)_{2} \mathrm{SiF}_{6}$ aqueous solution treatment. The influences of both matrix and $\mathrm{Sn}$ loading on the formation of Lewis acid sites on Sn-containing catalysts prepared with the DP process can be seen more clearly from Figure 8. It is obvious that the defective S-1 zeolite and its defect density are of significance for the acidity enhancement. Further, taking the $\mathrm{H}_{2}$-TPR profiles (Figure 3) and the hydroxyls stretching FT-IR spectra of defective S- 1 and the Sn-containing defective S- 1 zeolite catalysts with different Sn loadings (Figure 5) into consideration, it is reasonable to think that the combination of nano-sized $\mathrm{SnO}_{2}$ clusters with the hydroxyl nests of the defective S-1 zeolite should be the necessities of the increases of Lewis acid amount and acid strength in the S-1 zeolite.
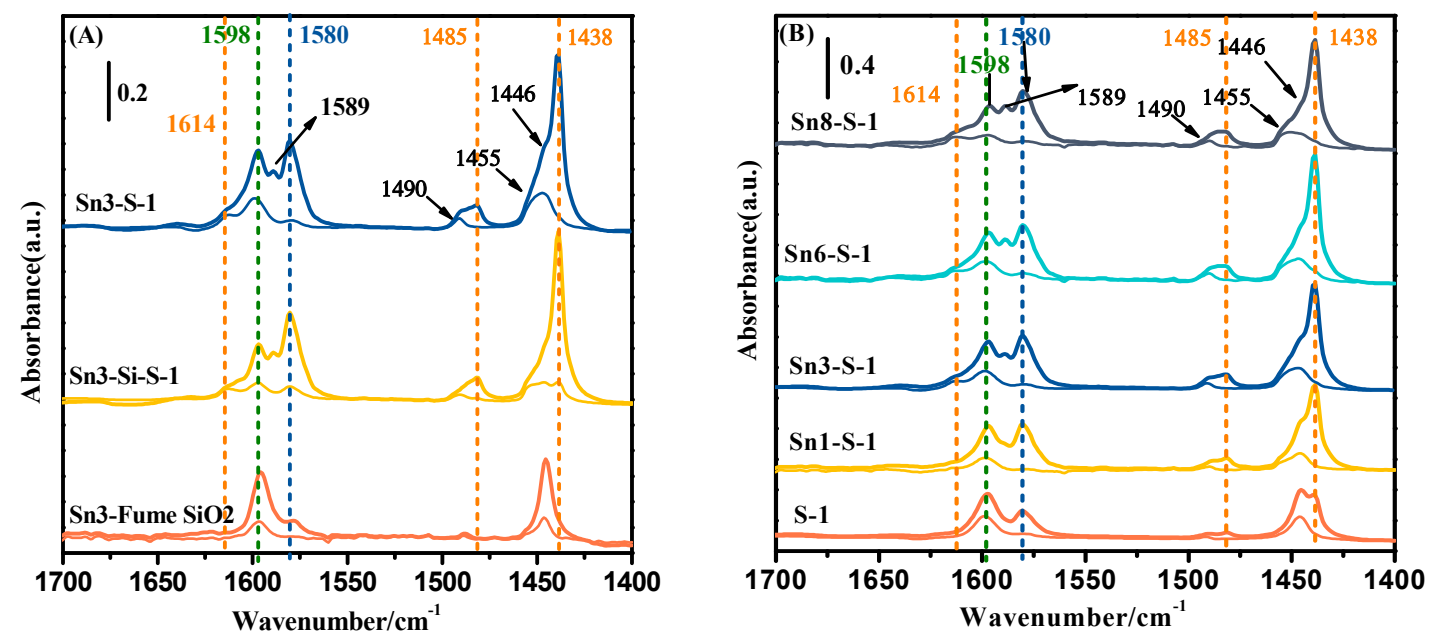

Figure 6. Pyridine adsorption FT-IR spectra of Sn-containing catalysts with different matrixes (A) and Sn-containing defective S-1 zeolite catalysts with different Sn loadings (B) (thick lines: evacuated at $200{ }^{\circ} \mathrm{C}$; thin lines: evacuated at $350{ }^{\circ} \mathrm{C}$ ).
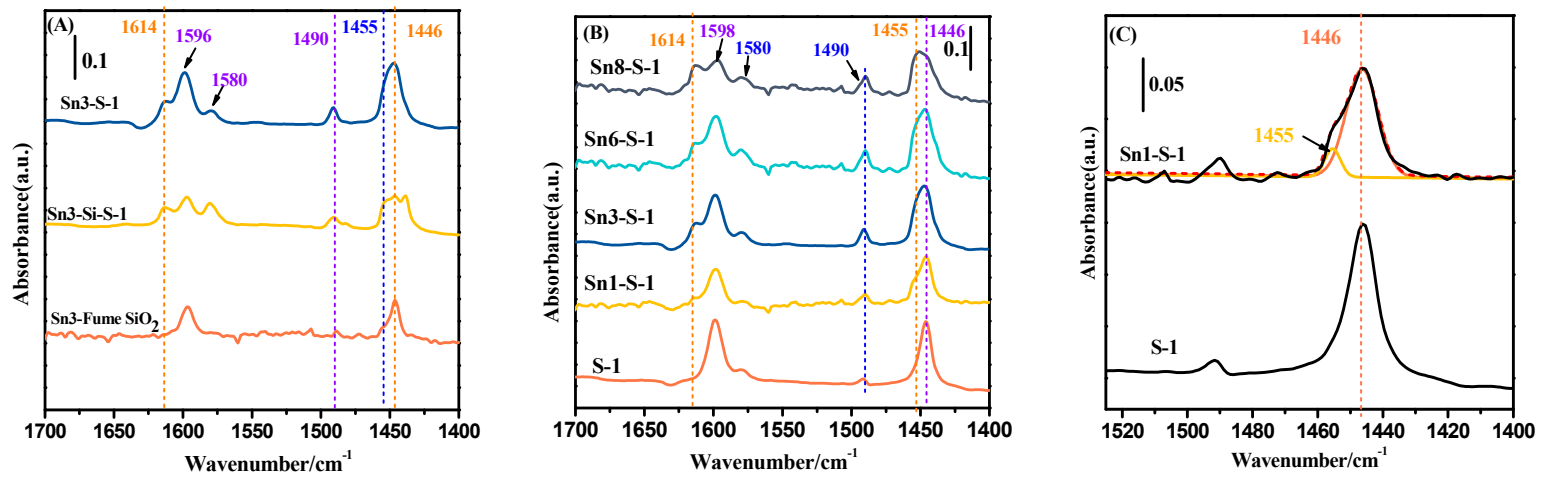

Figure 7. Pyridine adsorption FT-IR spectra (evacuated at $350{ }^{\circ} \mathrm{C}$ ) of Sn-containing catalysts with different matrixes (A), Sn-containing defective S-1 zeolite catalysts with different Sn loadings (B) and the deconvolution of the main absorption band of Sn1-S-1 sample at low frequency (C). 

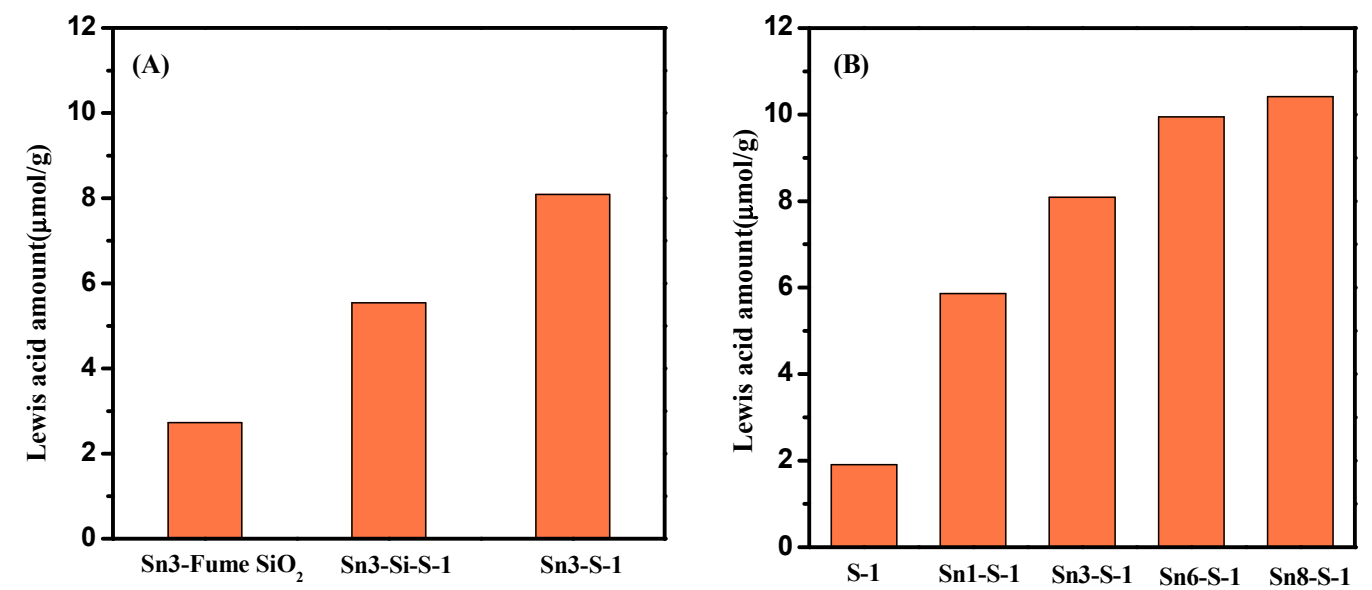

Figure 8. Dependences of the number of Lewis acid sites (estimated with the $1455 \mathrm{~cm}^{-1}$ band of pyridine adsorption FT-IR spectra after evacuation at $350^{\circ} \mathrm{C}$, following the procedures reported in $[39,40]$ ) of the Sn-containing catalysts on matrix (A) and Sn loading (B).

\subsection{Catalytic Performance of the Stannic Oxide Modified Defective S-1 Zeolite}

In order to evaluate the catalytic performance of the acidity of defective S- 1 zeolite and its Sn-containing counterparts, the intermolecular condensations of EDA to PIP and TEDA were chosen as a probe reaction. The main reaction paths of EDA on solid acid catalyst is as Scheme $1[8,11]$.

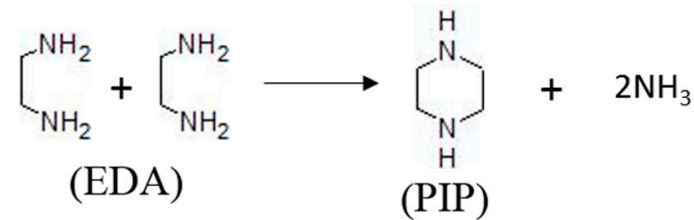<smiles>NCCNCC1CN2CCN(C1)C2</smiles><smiles>c1cc(C2CCCCC2)c[nH]1</smiles>

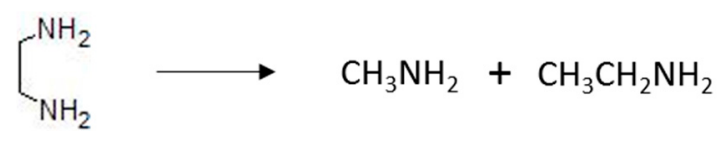<smiles>CCc1nccnc1C[CH+]Cc1cnccn1</smiles>

Scheme 1. The main reaction paths of ethylenediamine (EDA) over solid acid catalyst $[8,11]$. ((1)-(2): Main reactions; (3)-(5): Side reactions).

The condensation of EDA over solid acid catalyst is commonly conducted at atmospheric pressure and gas-phase condition. The reactant and the major products involved are of strong organic bases. Accord to literature [41], the gas-phase basicity (GB) of EDA, PIP, and TEDA are very close to that of pyridine. Moreover, the heterocyclic amines like PIP and TEDA also have a similar molecule structure 
to pyridine. This is one of the reasons why the intermolecular condensation of EDA was selected as a probe reaction for studying the catalysts' reaction performance.

Figure 9 shows that the conversion of $\mathrm{EDA}$ over bulk $\mathrm{SnO}_{2}$ and fume $\mathrm{SiO}_{2}$ was near zero. Both the defective S-1 zeolite and the "perfect" S-1 (Si-S-1) zeolite with low density of hydroxyl nests have inferior activity for the conversion of EDA as well. However, the activity of the former was much higher than that of the latter. Looking back to the acidity characterization in Figure 7B, one can see that the defective S-1 zeolite matrix certainly had a little acidity as indicated by the appearance of a small absorption band at $1490 \mathrm{~cm}^{-1}$ after evacuation at $350{ }^{\circ} \mathrm{C}$, but the acidity of the "perfect" Si-S- 1 zeolite, especially that of the fume $\mathrm{SiO}_{2}$, was too weak to be observed at evacuation at $350{ }^{\circ} \mathrm{C}$. Therefore, the conversions of EDA over different matrixes agreed well with the acidities of these siliceous materials. The modification of fume $\mathrm{SiO}_{2}$, Si-S-1, and S- 1 with $\mathrm{SnO}_{2}$ via the DP process remarkably enhanced the conversion of EDA over these modified matrixes. By contrast, the modification of defective S-1 zeolite with $\mathrm{SnO}_{2}$ resulted in the most active catalyst (Sn3-S-1), which exhibits 79\% EDA conversion, while the catalysts obtained with Si-S- 1 and fume $\mathrm{SiO}_{2}$ acquired much lower activities; the EDA conversions over them were $59 \%$ and $12 \%$, respectively. One can again see from Figure 7A that conversions of EDA over the Sn-containing catalysts (Sn loading was $3 \mathrm{wt} . \%$ ) coincided well with their acidities characterized by pyridine adsorption FT-IR (bands at $1614 \mathrm{~cm}^{-1}, 1490 \mathrm{~cm}^{-1}$, and $1455 \mathrm{~cm}^{-1}$ ). The ratios of TEDA/PIP over Sn3-fume $\mathrm{SiO}_{2}$, Sn3-Si-S-1, and Sn3-S-1 catalysts were calculated to be $0.67,0.78$, and 1.63, respectively. Generally, the formation of TEDA from the condensation of PIP with EDA needs stronger acid sites. Therefore, the increase of the TEDA/PIP ratio in the sequence of $\mathrm{Sn} 3$-fume $\mathrm{SiO}_{2}$, Sn3-Si-S-1, and Sn3-S-1 also suggested an increase of the acidity of the Sn-containing catalyst in the sequence of $\mathrm{Sn} 3$-fume $\mathrm{SiO}_{2}$, Sn3-Si-S-1, and Sn3-S-1. From these results we inferred that the defects of the S-1 zeolite, or in other words, the hydroxyl nests of the defective S-1 zeolites, took an important role in the acidity enhancement of $\mathrm{SnO}_{2}$ deposition modification.

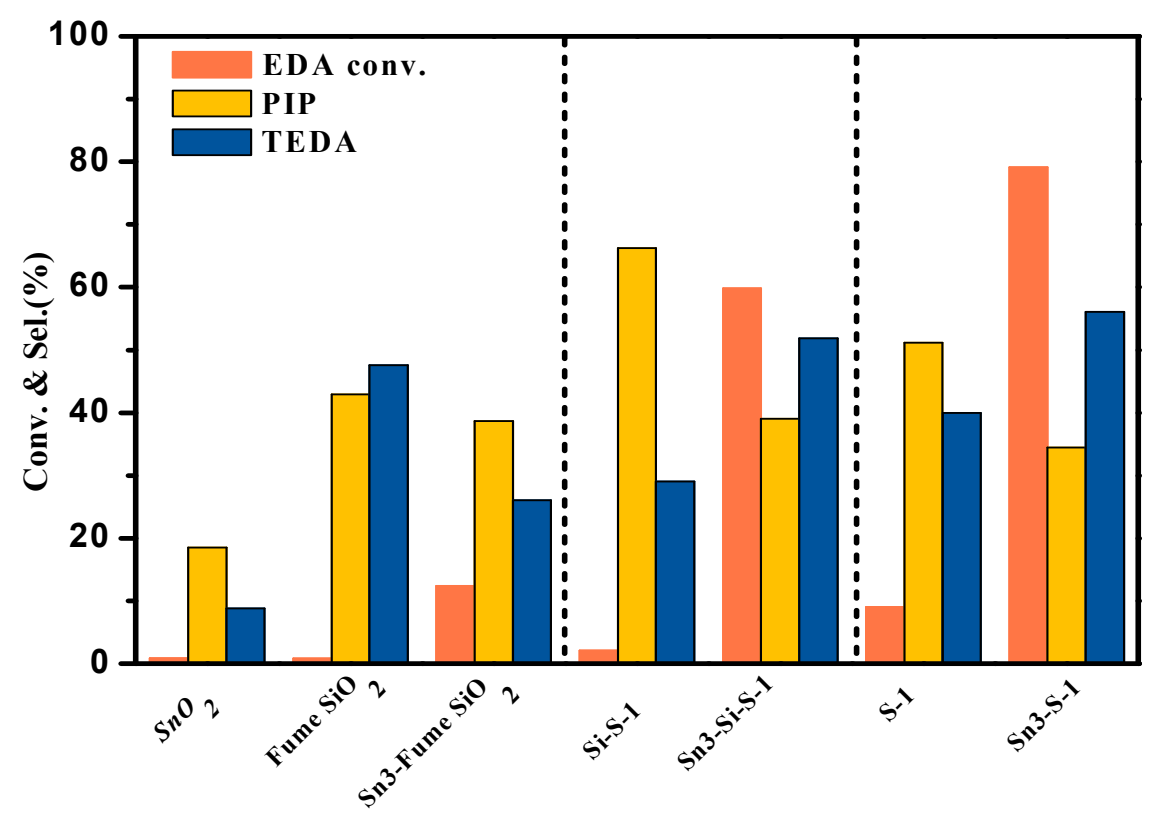

Figure 9. Catalytic performance of different catalysts in the intermolecular condensation of EDA to piperazine (PIP) and 1, 2-Diazabicyclo [2, 2, 2] octane (TEDA) (reaction conditions: $340{ }^{\circ} \mathrm{C}, \mathrm{EDA} / \mathrm{H}_{2} \mathrm{O}$ mass ratio $=0.9$, weight hourly space velocity (WHSV) of reactant solution $=1.3 \mathrm{~h}^{-1}$, time on stream $(\mathrm{TOS})=24 \mathrm{~h})$.

Figure 10 shows that $\mathrm{Sn}$ loading also has a significant influence on the catalytic performance of the $\mathrm{SnO}_{2}$ deposited defective S-1 zeolite catalyst. First of all, this can be seen from the evolution of EDA conversion. As the Sn loading increased, the EDA conversion increased first and then declined 
slightly. The maximum EDA conversion was obtained with $6 \mathrm{wt.} \% \mathrm{Sn}$ loading. Interestingly, at low Sn loading (1 wt.\%), a small increase of Sn loading had a very big promotion effect on the conversion of EDA; the conversion of EDA was increased from 9\% (S-1) to 70.55\% (Sn1-S-1), and the increment was almost 7 times. In addition, the dependence of the product (PIP and TEDA) selectivity on Sn loading is also impressive. The defective S-1 zeolite matrix produced more PIP than TEDA. However, in the case of Sn-containing zeolite catalysts, the product was dominated by TEDA, and this overturn happened right in the lowest $\mathrm{Sn}$ loading (1 wt.\%). Once more, from Figures $7 \mathrm{~B}$ and 10 it is easy to see that the change of the acidity of the Sn-containing defective S-1 zeolite as Sn loading increased is in line with the catalytic performance change of the catalyst series. The enhancement of the acidity of the defective S-1 zeolite by the $\mathrm{SnO}_{2}$ deposition modification not only increased the catalytic activity of the defective S-1 zeolite but also adjusted the product selectivity of the zeolite in the intermolecular condensation of EDA. On account of the higher additional value of TEDA than PIP, the increase of TEDA selectivity via enhancing the acidity of the defective S-1 zeolite with $\mathrm{SnO}_{2}$ deposition modification has practical significance for the intermolecular condensation of EDA. As to the slight decline of the activity of the modified catalyst with very high Sn loading (e.g., 8 wt.\%), we tend to think that it was mainly caused by the inaccessibleness of some of the catalysts' active sites at very high Sn loading, but this issue must be made certain in the future work.

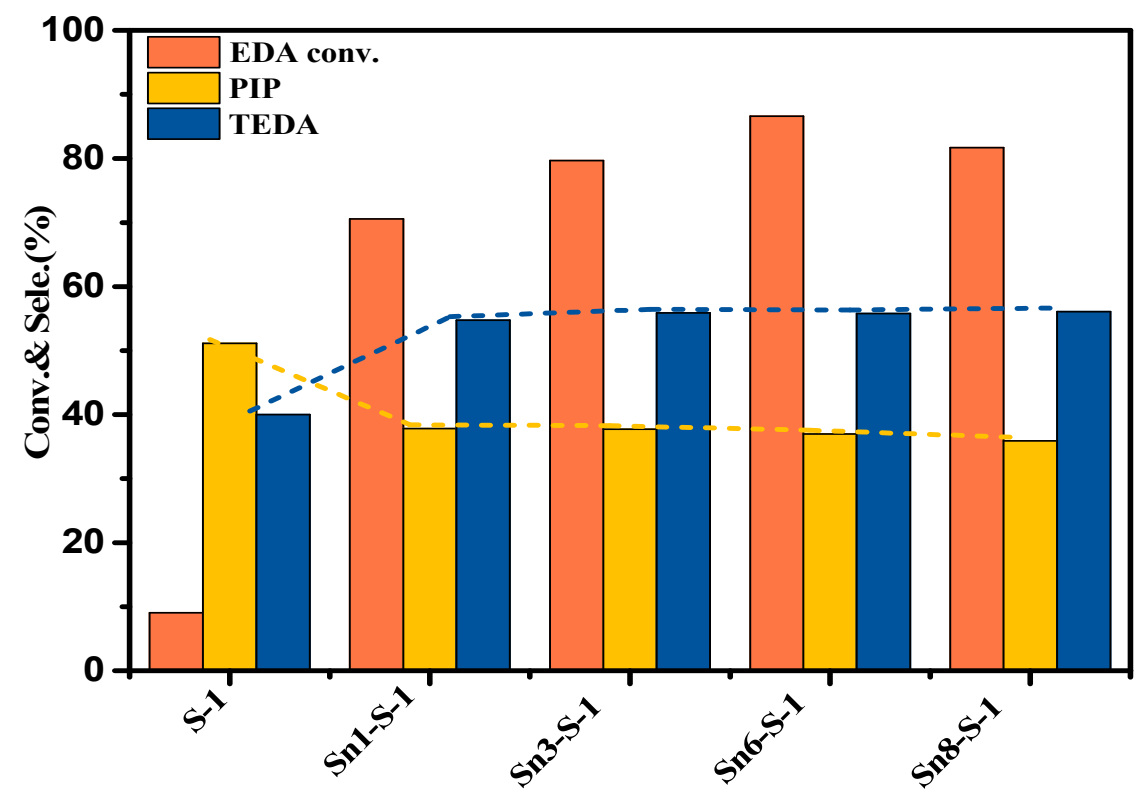

Figure 10. Effect of Sn loading on the conversion of EDA and the selectivity (to PIP and TEDA) of Sn-x-S-1 catalysts (for reaction conditions, see Figure 9).

In order to know whether or not the highly alkaline EDA reactant and TEDA and PIP products involved in the intermolecular condensation can avoid the strong adsorption on the acidity enhanced defective S-1 zeolite, so as to guarantee a stable reaction activity, a preliminary durability test was conducted with selected catalyst Sn6-S-1. Figure 11 shows that the condensation of EDA could conduct smoothly over the $\mathrm{SnO}_{2}$ modified catalyst within $80 \mathrm{~h}$, which implies that the acidification of the defective S-1 zeolite by $\mathrm{SnO}_{2}$ deposition modification did not result in the strong adsorption of the highly alkaline EDA and TEDA and PIP on the modified catalyst. Thus, the defective S-1 zeolite modified with the $\mathrm{SnO}_{2}$ deposition method could be a suitable catalyst for reactions involving highly alkaline reactants and products. In future study, the coking deactivation and coke-burning regeneration of the Sn-containing defective S-1 catalyst will be investigated in detail. 


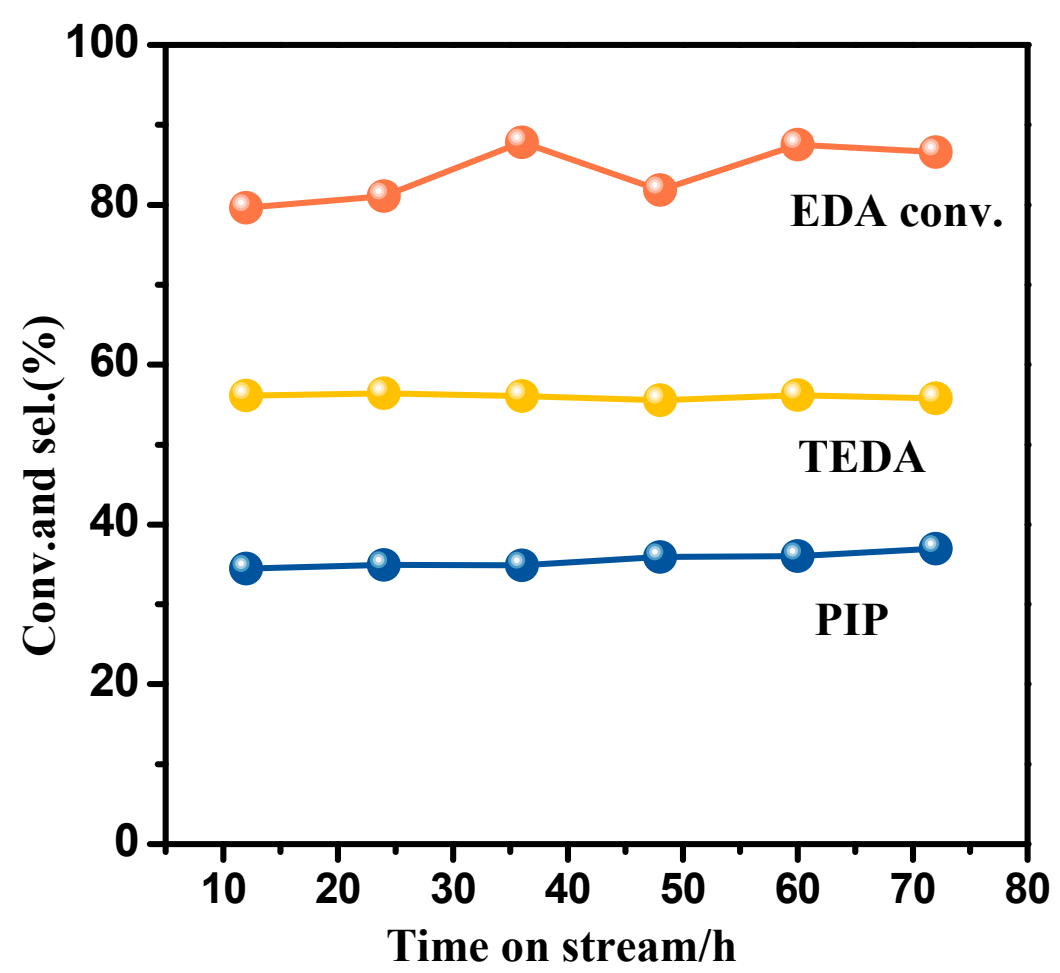

Figure 11. Reaction stability of Sn-containing defective S-1 zeolite catalyst Sn6-S-1 (6 wt.\% Sn loading) in the intermolecular condensation of EDA to PIP and TEDA (for reaction conditions, see Figure 9).

\section{Materials and Methods}

\subsection{Catalyst Preparation}

The defective S-1 zeolite parent was manufactured by DQ Tech Chemical Technology (Dalian, China). Before use, the defective S- 1 parent was dried at $110{ }^{\circ} \mathrm{C}$ and then calcined at $550{ }^{\circ} \mathrm{C}$. For the purpose of comparison, a "perfect" S-1 zeolite (Si-S-1) with low density of silanol nest was prepared by treating the defective S-1 parent with $0.025 \mathrm{M}\left(\mathrm{NH}_{4}\right)_{2} \mathrm{SiF}_{6}$ (Aladdin, Shanghai, China)aqueous solution at $80^{\circ} \mathrm{C}$ for $10 \mathrm{~h}$ according to the described procedure [42]. Then, the treated zeolite was recovered and dried at $110{ }^{\circ} \mathrm{C}$ overnight, which was followed by calcination at $540{ }^{\circ} \mathrm{C}$ for $6 \mathrm{~h}$. In addition to the S-1 zeolites, a kind of amorphous silica (fume $\mathrm{SiO}_{2}$ ) (Evonik Industries AG, Frankfurt, Germany) was also employed as a matrix in the DP process for comparison.

Details of the DP process used in this study are as follows. First, an alcohol solution was prepared by dissolving a certain amount of $\mathrm{SnCl}_{2} \cdot 2 \mathrm{H}_{2} \mathrm{O}$ (Damao, Tianjin, China) in it. Second, powder sample of the calcined S-1 zeolites or fume $\mathrm{SiO}_{2}$ was dispersed in the solution under vigorous agitation. The dispersion was allowed for $20 \mathrm{~min}$. It was followed by adding excess ammonium hydroxide solution ( $25 \mathrm{wt} . \%)$ into the slurry. After that, the mixture was agitated at $80{ }^{\circ} \mathrm{C}$ for $5 \mathrm{~h}$. Finally, the mixture was evaporated to dryness at $110{ }^{\circ} \mathrm{C}$ and calcined at $550{ }^{\circ} \mathrm{C}$ for $6 \mathrm{~h}$ to obtain the Sn-containing catalyst samples.

\subsection{Catalyst Characterizations}

Catalyst samples were characterized by scanning electron microscope (SEM), UV-visible spectroscopy (UV-VIS), nitrogen physisorption, Fourier transform infrared spectroscopy (FT-IR), and $\mathrm{H}_{2}$-TPR techniques. SEM images were taken on a Hitachi S-4800 microscope. The UV-VIS spectra were recorded on a JASCOV-550 spectrometer (JASCO, Tokyo, Japan) using $\mathrm{BaSO}_{4}$ as reference. The $\mathrm{H}_{2}$-TPR experiments were carried out with a Quanta chrome ChemBet 3000 chemisorb (Shimadzu, Kyoto, Japan) instrument. In order to obtain the TPR profiles, sample (150 mg, 380-830 $\mu \mathrm{m}$ sieve 
fraction) was placed in a quartz tube between two quartz wool plugs and introduced into an oven. Prior to reduction, the sample was calcined at $450{ }^{\circ} \mathrm{C}\left(10{ }^{\circ} \mathrm{C} \min ^{-1}\right)$ in $5 \% \mathrm{O}_{2}$ in He for $1 \mathrm{~h}$. Then, the sample was cooled down to room temperature in a $\mathrm{N}_{2}$ flow. The temperature-programmed reduction ( TPR) measurements were performed in a flow of 5 vol. $\% \mathrm{H}_{2}$ in $\mathrm{N}_{2}$ under heating at a ramp of $10^{\circ} \mathrm{C} \mathrm{min}^{-1}$ until the temperature of $800^{\circ} \mathrm{C}$ was reached. The spectrum of surface hydroxyl $(\mathrm{OH})$ vibration was obtained with a Nicolet is10 FT-IR spectrometer (Thermo Fisher Scientific, Waltham, MA, USA) using transmission mode. To do this, catalyst sample was pressed into a self-supporting thin wafer (approximately $15 \mathrm{mg}$ ) and decontaminated at $400{ }^{\circ} \mathrm{C}$ under vacuum $\left(10^{-3} \mathrm{pa}\right)$ for $4 \mathrm{~h}$ in a quartz IR cell equipped with $\mathrm{CaF}_{2}$ windows. After the pretreatment, the cell was cooled down to room temperature for spectrum recording. The spectrum was recorded from 4000 to $400 \mathrm{~cm}^{-1}$ with an optical resolution of $4 \mathrm{~cm}^{-1}$. The hydroxyl vibration spectra were obtained by subtracting the background spectrum (recorded with an empty IR cell in the absence of sample) from the measured sample spectra. The pyridine IR spectra were also recorded with a Nicolet 10 FT-IR spectrometer using transmission mode in the range from 4000 to $400 \mathrm{~cm}^{-1}$ with an optical resolution of $4 \mathrm{~cm}^{-1}$. The pretreatment of catalysts was the same as that for obtaining surface hydroxyl spectra. The spectra of the adsorbed pyridine were obtained as follows: First, pyridine adsorption was carried out at $35^{\circ} \mathrm{C}$; second, the evacuation treatment $\left(10^{-3} \mathrm{pa}\right)$ was conducted for $30 \mathrm{~min}$ at $200{ }^{\circ} \mathrm{C}$ and $350{ }^{\circ} \mathrm{C}$; then the cell was cooled down to room temperature for spectra recording; finally, the spectra were obtained by subtracting the background spectrum (sample spectrum before pyridine adsorption) from the measured spectra. All IR spectra have been normalized by sample mass.

\subsection{Catalytic Tests}

The probe reaction of EDA intermolecular condensation was carried out on a top-flow fixed-bed tubular reactor at atmospheric pressure. The inner diameter of the fixed-bed reactor was $10 \mathrm{~mm}$ (catalyst loading $1 \mathrm{~g}$ ). Binder-free catalysts, which were always loaded in the thermostatic region of the reactor, were pressed and crushed in the size of 20-40 mesh and calcined at $540{ }^{\circ} \mathrm{C}$ for $3 \mathrm{~h}$ before use. The reaction conditions were as follows: $340^{\circ} \mathrm{C}, \mathrm{EDA} / \mathrm{H}_{2} \mathrm{O}$ mass ratio $=0.9$, and the weight hourly space velocity (WHSV) of the reactant solution was $1.3 \mathrm{~h}^{-1}$. Liquid products of the reaction were collected by a cooling trap and sampling every $12 \mathrm{~h}$. The products were analyzed by a Shimadzu 2010 gas chromatograph equipped with a SE-54 column $(30 \mathrm{~mm} \times 0.53 \mathrm{~mm} \times 1.0 \mu \mathrm{m})$ and a FID detector. The conversion of EDA and the selectivity of TEDA and PIP were calculated as follows:

$$
\begin{gathered}
\text { Conversion of EDA: EDA conv. }=\sum \mathrm{Ai} /\left(\sum \mathrm{Ai}+\mathrm{A}_{\mathrm{EDA}} \text { in products }\right) \times 100 \% \\
\text { Selectivity of TEDA: TEDA selec. }=\mathrm{A}_{\mathrm{TEDA}} / \sum \mathrm{Ai} \times 100 \% \\
\text { Selectivity of PIP: PIP selec. }=\mathrm{A}_{\mathrm{PIP}} / \sum \mathrm{Ai} \times 100 \%
\end{gathered}
$$

where $\mathrm{A}_{\mathrm{TEDA}}, \mathrm{A}_{\mathrm{PIP}}$, and $\mathrm{A}_{\mathrm{EDA}}$ in products were obtained according to the following formula:

$$
A i=f i \times A^{\prime} i
$$

where $A^{\prime} i$ is the area percentage of TEDA, PIP, and EDA obtained in the gas chromatograph analysis. $\mathrm{fi}$ is the relative mass correction factor which was determined with a self-prepared standard solution containing given amounts of TEDA, PIP, and EDA. $\sum$ Ai is the sum of the A value of all the products that appeared in the gas chromatograph analysis, including not only TEDA, PIP, and EDA but also other impurities. The relative mass correction factors of the impurities were arbitrarily determined as 1.0 .

\section{Conclusions}

The acidity of defective S- 1 zeolite was successfully enhanced by a facile $\mathrm{SnO}_{2}$ precipitationdeposition method. The acidified defective S-1 zeolite catalyst showed remarkably improved catalytic 
performance for the intermolecular condensation of EDA to PIP and TEDA, compared with the inactive zeolite parent. Catalyst characterizations suggest that both the hydroxyl nests of the defective S-1 zeolite and the dispersed $\mathrm{SnO}_{2}$ clusters should be the important factors for the formation of mild Lewis acid sites on the defective zeolite. Based on the catalytic performance of the stannic species modified defective S-1 zeolite in the conversion of EDA to PIP and TEDA, it is estimated that the $\mathrm{SnO}_{2}$ mildly acidified defective S-1 zeolite might become a very active and durable catalyst for reactions involving highly alkaline reactants and products.

Author Contributions: Conceptualization, Y.Z.; software, X.Z.; validation, Q.Z. and L.L.; formal analysis, Y.Z.; investigation, Y.Z.; resources, C.L.; data curation, Y.Z.; writing — original draft preparation, Y.Z.; writing—review and editing, H.G.; supervision, H.G.; project administration, H.G. All authors have read and agreed to the published version of the manuscript.

Funding: This research received no external funding.

Conflicts of Interest: The authors declare no conflict of interest.

\section{References}

1. Corma, A. Inorganic Solid Acids and Their Use in Acid-Catalyzed Hydrocarbon Reactions. Chem. Rev. 1995, 95, 559-614. [CrossRef]

2. International Zeolite Association Database of Zeolite Structures. Available online: http://www.iza-structure. org/databases/ (accessed on 17 January 2020).

3. Martín, N.; Dusselier, M.; De Vos, D.E.; Cirujano, F.G. Metal-Organic framework derived metal oxide clusters in porous aluminosilicates: A catalyst design for the synthesis of bioactive aza-heterocycles. Acs Catal. 2018, 9, 44-48. [CrossRef]

4. Farkas, A.; Mills, G.A.; Erner, W.E.; Maerker, J.B. Triethylenediamine-A new bicyclic intermediate and catalyst for making polyurethane foam. Ind. Eng. Chem. 1959, 51, 1299-1300. [CrossRef]

5. Shah, A.; Shah, A.H.; Parveen, N. Synthesis and electrochemical investigations of piperazines. Electrochim. Acta 2016, 220, 705-711. [CrossRef]

6. Yu, C.H.; Huang, C.H.; Tan, C.S. A review of $\mathrm{CO}_{2}$ capture by absorption and adsorption. Aerosol Air Qual. Res. 2012, 12, 745-769. [CrossRef]

7. Weitkamp, J.; Ernst, S.; Buysch, H.J. Synthesis of piperazine and triethylenediamine using ZSM-5-type zeolite catalysts. Stud. Surf. Sci. Catal. 1991, 65, 297-304.

8. Reichle, W.T. Reactions of Aliphatic $\alpha$ - $\omega$-Diamines in $\mathrm{H}^{+}$-Pentasils. J. Catal. 1993, 144, 556-568. [CrossRef]

9. Santiesteban, J.G.; Li, H.X.; Armor, J.N. Production of Triethylenediamine Using Surface Acidity Deactivated Zeolite Catalysts. U.S. Patent 5,741,906, 21 April 1998.

10. Frauenkron, M.; Stein, B. Process for the Preparation of Triethylenediamine (TEDA). U.S. Patent 7,115,742, 3 October 2006.

11. Wang, Y.; Liu, Y.; Li, X. Intermolecular condensation of ethylenediamine to 1,4-diazabicyclo [2,2,2] octane over TS-1 catalysts. J. Catal. 2009, 266, 258-267. [CrossRef]

12. Heitmann, G.P.; Dahlhoff, G.; Holderich, W.F. Catalytically Active Sites for the Beckmann Rearrangement of Cyclohexanone Oxime to $\varepsilon$-Caprolactam. J. Catal. 1999, 186, 12-19. [CrossRef]

13. Ichihashi, H.; Sato, H. The development of new heterogeneous catalytic processes for the production of-caprolactam. Appl. Catal. A Gen. 2001, 221, 359-366. [CrossRef]

14. Bonelli, B.; Forni, L.; Aloise, A. Beckmann rearrangement reaction: About the role of defect groups in high silica zeolite catalysts. Microporous Mesoporous Mater. 2007, 101, 153-160. [CrossRef]

15. Izumi, Y.; Ichihashi, H.; Shimazu, Y. Development and industrialization of the vapor-phase Beckmann rearrangement process. Bull. Chem. Soc. Jpn. 2007, 80, 1280-1287. [CrossRef]

16. Ferrini, P.; Dijkmans, J.; De Clercq, R. Lewis acid catalysis on single site Sn centers incorporated into silica hosts. Coord. Chem. Rev. 2017, 343, 220-255. [CrossRef]

17. Dapsens, P.Y.; Mondelli, C.; Pérez-Ramírez, J. Design of Lewis-acid centres in zeolitic matrices for the conversion of renewables. Chem. Soc. Rev. 2015, 44, 7025-7043. [CrossRef] 
18. Mal, N.K.; Ramaswamy, A.V. Hydroxylation of phenol over Sn-silicalite-1 molecular sieve: Solvent effects. J. Mol. Catal. A Chem. 1996, 105, 149-158. [CrossRef]

19. Niphadkar, P.S.; Joshi, P.N.; Gurav, H.R. Synthesis of N-methylaniline by aniline alkylation with methanol over Sn-MFI molecular sieve. Catal. Lett. 2009, 133, 175. [CrossRef]

20. Dapsens, P.Y.; Mondelli, C.; Jagielski, J. Hierarchical Sn-MFI zeolites prepared by facile top-down methods for sugar isomerisation. Catal. Sci. Technol. 2014, 4, 2302. [CrossRef]

21. Dapsens, P.Y.; Mondelli, C.; Kusema, B.T. A continuous process for glyoxal valorisation using tailored Lewis-acid zeolite catalysts. Green Chem. 2014, 16, 1176-1186. [CrossRef]

22. Morales, M. Environmental and economic assessment of lactic acid production from glycerol using cascade bio-and chemocatalysis. Energy Environ. Sci. 2015, 8, 558-567. [CrossRef]

23. Dai, W.; Wang, C.; Tang, B. Lewis acid catalysis confined in zeolite cages as a strategy for sustainable heterogeneous hydration of epoxides. ACS Catal. 2016, 6, 2955-2964. [CrossRef]

24. Dijkmans, J.; Gabriëls, D.; Dusselier, M. Productive sugar isomerization with highly active Sn in dealuminated $\beta$ zeolites. Green Chem. 2013, 15, 2777-2785. [CrossRef]

25. Yuan, E.; Dai, W.; Wu, G. Facile synthesis of Sn-containing MFI zeolites as versatile solid acid catalysts. Microporous Mesoporous Mater. 2018, 270, 265-273. [CrossRef]

26. Bermejo-Deval, R.; Gounder, R.; Davis, M.E. Framework and extraframework tin sites in zeolite beta react glucose differently. Acs Catal. 2012, 2, 2705-2713. [CrossRef]

27. Dijkmans, J.; Dusselier, M.; Janssens, W.; Trekels, M.; Vantomme, A.; Breynaert, E.; Kirschhock, C.; Sels, B.F. An inner-/outer-sphere stabilized $S n$ active site in $\beta$-zeolite: Spectroscopic evidence and kinetic consequences. Acs Catal. 2015, 6, 31-46. [CrossRef]

28. Marcella, T.; Guido, B.; Stefano, R. FT-IR Studies on Light Olefin Skeletal Isomerization Catalysis: III. Surface Acidity and Activity of Amorphous and Crystalline Catalysts Belonging to the $\mathrm{SiO}_{2}-\mathrm{Al}_{2} \mathrm{O}_{3}$ System. J. Catal. 1998, 179, 581-596.

29. Ichihashi, H.; Ishida, M.; Shiga, A. The Catalysis of Vapor-Phase Beckmann Rearrangement for the Production of $\varepsilon$-Caprolactam. Catal. Surv. Asia 2003, 7, 261-270. [CrossRef]

30. Xia, C.; Liu, Y.; Lin, M. Confirmation of the isomorphous substitution by Sn atoms in the framework positions of MFI-typed zeolite. Catal. Today 2018, 316, 193-198. [CrossRef]

31. Niphadkar, P.S.; Patil, K.R.; Joshi, P.N. Characterization of surface acid sites in tin-silicalite-1 (Sn-MFI) molecular sieve by X-ray photoelectron spectroscopy. Microporous Mesoporous Mater. 2011, 141, 236-240. [CrossRef]

32. Cho, H.J.; Dornath, P.; Fan, W. Synthesis of hierarchical Sn-MFI as Lewis acid catalysts for isomerization of cellulosic sugars. Acs Catal. 2014, 4, 2029-2037. [CrossRef]

33. Zhu, Z.; Xu, H.; Jiang, J. Sn-Beta zeolite derived from a precursor synthesized via an organotemplate-free route as efficient Lewis acid catalyst. Appl. Catal. A Gen. 2018, 556, 52-63. [CrossRef]

34. Yang, X.; Bian, J.; Huang, J. Fluoride-free and low concentration template synthesis of hierarchical Sn-Beta zeolites: Efficient catalysts for conversion of glucose to alkyl lactate. Green Chem. 2017, 19, 692-701. [CrossRef]

35. Casagrande, M.; Moretti, E.; Storaro, L.; Lenarda, M.; Gersich, J.; Stievano, L.; Wagner, F.E. Synthesis and structural characterization of MSU-type silica-tin molecular sieves: Post-synthesis grafting of tin chlorides. Microporous Mesoporous Mater. 2006, 91, 261-267. [CrossRef]

36. de Clippel, F.; Dusselier, M.; Van Rompaey, R. Fast and selective sugar conversion to alkyl lactate and lactic acid with bifunctional carbon-silica catalysts. J. Am. Chem. Soc. 2012, 134, 10089-10101. [CrossRef]

37. Li, L.; Stroobants, C.; Lin, K. Selective conversion of trioses to lactates over Lewis acid heterogeneous catalysts. Green Chem. 2011, 13, 1175-1181. [CrossRef]

38. Emeis, C.A. Determination of integrated molar extinction coefficients for infrared absorption bands of pyridine adsorbed on solid acid catalysts. J. Catal. 1993, 141, 347-354. [CrossRef]

39. Beletskiy, E.V.; Hou, X.; Shen, Z. Supported tetrahedral oxo-Sn catalyst: Single site, two modes of catalysis. J. Am. Chem. Soc. 2016, 138, 4294-4297. [CrossRef]

40. Janiszewska, E.; Macario, A.; Wilk, J. The role of the defect groups on the Silicalite-1 zeolite catalytic behavior. Microporous Mesoporous Mater. 2013, 182, 220-228. [CrossRef] 
41. Hunter, E.P.; Lias, S.G. Evaluated gas phase basicities and proton affinities of molecules: An update. J. Phys. Chem. Ref. Data 1998, 27, 413-656. [CrossRef]

42. Han, S.; Shihabi, D.S.; Chang, C.D. Selective removal of surface acidity in ZSM-5 zeolite using $\left(\mathrm{NH}_{4}\right)_{2} \mathrm{SiF} 6$ treatment. J. Catal. 2000, 196, 375-378. [CrossRef] 